\title{
Muscle regeneration is undisturbed by repeated polytraumatic injury
}

\author{
D. B. Horváthy $\cdot$ P. P. Nardai · T. Major • \\ K. Schandl · A. Cselenyák · G. Vácz • \\ L. Kiss $\cdot$ M. Szendröi $\cdot$ Z. Lacza
}

Received: 24 January 2010/Accepted: 31 May 2010/Published online: 8 July 2010

(C) The Author(s) 2010. This article is published with open access at Springerlink.com

\begin{abstract}
Introduction Clinical observations suggest that repeated injury within a week after a traumatic event impairs the regeneration of tissues. Our aim was to investigate the effect of repeated trauma on the proliferation of satellite cells in skeletal muscle tissue.

Materials and methods Cold lesion injury was performed in the soleus muscle and in the motor cortex of anesthetized male Wistar rats 0,1 , or 2 times with 7 day intervals between the interventions. Following the last operation, 5-bromo-2'-deoxyuridine was injected i.p. for 6 or 12 days to label dividing cells. Gut epithelium was used as positive control. Immunohistochemistry was performed 1 and 5 weeks after the last injury and the sections were analyzed with confocal microscopy.

Results In the case of repeated trauma, the percentage of proliferating cells remained the same compared to single hit animals after 1 week $(28.0 \pm 2.5 \%$ and $29.6 \pm 3.0 \%)$ as well as after 5 weeks $(13.9 \pm 1.8 \%$ and $14.5 \pm 2.2 \%)$. Conclusion The second hit phenomenon is probably due to systemic factors rather than to a diminished regenerating potential of injured soft tissues.
\end{abstract}

Keywords Skeletal muscle $\cdot$ Satellite cell $\cdot$ Cold lesion . Second hit · Polytrauma

D. B. Horváthy · P. P. Nardai - T. Major · K. Schandl ·

A. Cselenyák · G. Vácz · L. Kiss · Z. Lacza $(\bowtie)$ Institute of Human Physiology and Clinical Experimental Research, Semmelweis University, Tüzoltó utca 37-47, Budapest 1094, Hungary

e-mail: zlacza@mac.com

M. Szendrői · Z. Lacza Department of Orthopedics, Semmelweis University, Budapest, Hungary

\section{Introduction}

Severe trauma and polytrauma are still the main cause of death in people under the age of 40 [1]. The survival of polytrauma patients depends on three different factors, the so-called "hits". The first hit is the polytrauma itself, early therapeutic intervention is the second hit, and the individual response is the third hit [2]. As these clinical observations suggest, timing is highly important in polytrauma management because the early response mechanisms, such as coagulation cascade, kallikreinkinin system, complement system, acute phase reaction could be augmented by second hit injuries such as surgical treatments or microbiological invasions [3]. Second hits could also adversely affect the healing potential of skeletal muscle tissue [4]. Therefore, the timing of therapeutic interventions is not only important to prevent the polytrauma victim from a second hit-induced "deadly spiral", including systemic inflammatory response syndrome, but to avoid the decrease of tissue regeneration as well.

Skeletal muscle tissue mainly regenerates by stem cell mobilization [5]. It has its own stem cells, called satellite cells, which are capable of both self-renewal and differentiation [6]. These cells are quiescent muscle precursors, located between the basal lamina and the sarcolemma of the mature myofiber [7]. Following injury, some differentiate into muscle fibers, others form new satellite cells [8]. Satellite cells are the most important source of skeletal muscle remodeling, but recent studies have shown that hematopoietic stem cells residing in the bone marrow can also migrate to the skeletal muscle tissue and contribute to myofiber regeneration [9-11]. It was also shown that the level of proliferating stem cells increases in patients after severe trauma [12]. In these observations, irradiation was 
used to damage the muscle tissue, which affected the satellite cell pool by causing atrophy and inflammation, but bone marrow contributes to skeletal muscle regeneration in physiological situations as well [13]. Generally, this contribution is very low, but in some cases $5-12 \%$ of the differentiated cells are of bone marrow origin [14]. Since the regeneration of skeletal muscle tissue occurs mainly through the mobilization of satellite cells, it is possible that a repeated trauma adversely affects this process via the reduced number of these cells. The aim of the present study was to elucidate how the proliferation of satellite cells is affected in skeletal muscle tissue after a second polytraumatic injury.

\section{Materials and methods}

\section{Animals}

Male Wistar rats weighing 250-300 g were used. Animals were maintained on lab chow and tap water ad lib with a $12 \mathrm{~h}$ day-night cycle in the conventional animal facility of the Institute of Human Physiology and Clinical Experimental Research, Budapest. The investigation was approved by the local Animal Research Committee according to the guidelines for animal experimentation.

\section{Cold lesion polytraumatic injury}

Cold lesion injury was performed as described previously under halothane anesthesia [15]. Briefly, the skin over the soleus muscle and on the head was shaved and desinfected with Betadine ${ }^{\circledR}$. To reach the soleus muscle, the skin was incised and the muscle was prepared by atraumatic methods. Two nodes of non-absorbable sutures were used to indicate the injured area. In order to reach the brain tissue, the scalp was incised and a circular craniectomy was made over the left motor cortex, $2 \mathrm{~mm}$ anterior and posterior from the bregma suture, and $3 \mathrm{~mm}$ left from the sagittal suture. A high-speed diamond pointed microdrill (Dremel ${ }^{\circledR}$ ) was used to prepare the craniectomy. The bone was thinned over the left motor cortex, and the last layer was removed by a forceps. Cold lesion was performed with a nickel coated stamp to prevent sticking to the tissue. The stamp was a small cup with a $3 \mathrm{~mm}$ diameter pointed bottom, precooled to $60^{\circ} \mathrm{C}$ with the mixture of dry ice and acetone. The stamp was lowered with a micromanipulator to contact the soleus muscle or the dura mater for $1 \mathrm{~min}$. Trauma was induced by a freezing effect; mechanical force was negligible throughout the procedure. Following the cold lesion injury the wounds were closed and animals regained consciousness in their cages.
Repeated poly-trauma model

Two experimental groups were investigated in our experiments. One group received $1 \times$ cold on the first experimental day and sham-operated on the 7th day. In the other group the cold lesion procedure was repeated on the 7 th day to model repeated traumatic injury. Following the last cold lesion or sham operation, BrDU treatment $(50 \mathrm{mg} / \mathrm{kg}$, i.p.) was administered for 6 or 12 days. Different intervals were used because the proliferation in muscle, brain and gut tissue samples was investigated at two time points: 1 and 5 weeks after the last cold lesion or sham-operation (Fig. 1). A control, non-injured group received only BrDU treatment. Animals were sacrificed (pentobarbital, $1 \mathrm{ml} / \mathrm{kg}$, i.p.) and the collected tissues were stored in $4 \%$ formaldehyde. Since the gut epithelium is a highly regenerative tissue with a very fast turnover of the cells [16], samples were harvested and served as positive control of BrDU labeling.

\section{Immunohistochemistry}

Paraffin sections from formalin fixed tissues were treated with $50 \mathrm{ml} / \mathrm{U}$ deoxyribonuclease (Sigma, \#DN-25) and microwaved in Retrievagen A solution (BD Pharmingen, \#550524) to digest the cells' DNA. After blocking in 1.5\% normal goat serum, a mouse monoclonal anti-BrdU antibody (BD Pharmingen, \#555627) and rabbit anti-laminin (Sigma, \#L9393) were applied at 1:200 dilution. An Alexa Fluor 488 anti-mouse secondary antibody and Alexa Fluor 546 anti-rabbit antibody (Molecular Probes, \#A11001, \#A11010) were used to visualize the labeling at 1:200 dilution and Hoechst nuclear staining (Invitrogen, \#33342) at 1:1,000 dilution was used to label the nuclei of the cells.

To visualize the samples, a Zeiss LSM 510 META confocal microscope (Carl Zeiss, Jena, Germany) was used. The BrdU positive cells selected by fluorescence were counted in a blind fashion with the software ImageJ (National Institute of Health, USA) in four fields of view at $63 \times$ magnification. Special care was taken to localize the injury in brain and muscle tissue during immunohistochemical analysis. We specified three different regions: intact tissue, penumbra and necrotic zones (Fig. 2). The penumbra region of the sections was investigated to calculate the number proliferating cells.

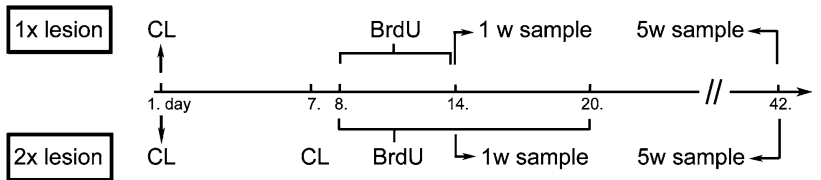

Fig. 1 Timeline of the experimental protocol. Control groups were sham operated without cold lesion $(C L)$ 
Fig. 2 Skeletal muscle morphology 1 week after trauma. Red color represents the nuclear Hoechst staining. Green color refers to BrdU staining. Co-localization of the signals (yellow color) represents the newly divided cells. Blue color refers to laminin-staining. Three different regions can be identified: intact muscle, a necrotic core, and a penumbra which is characterized by disturbed myofibers and a high percentage of proliferating cells

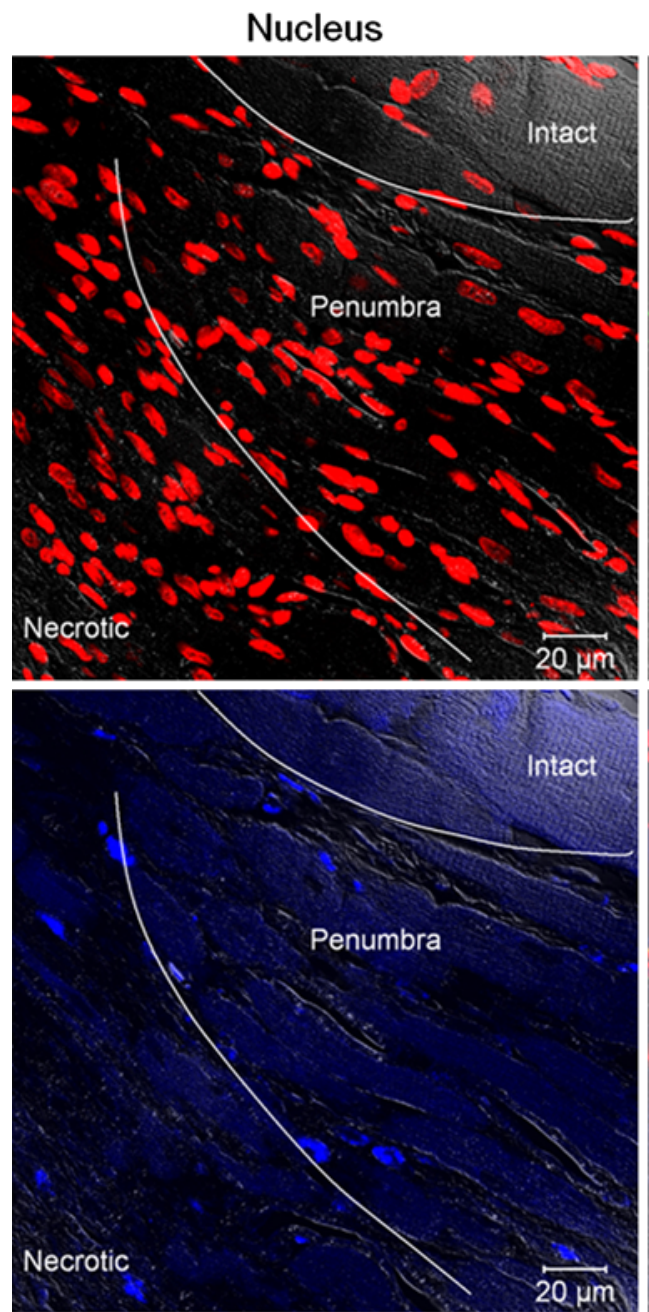

Laminin
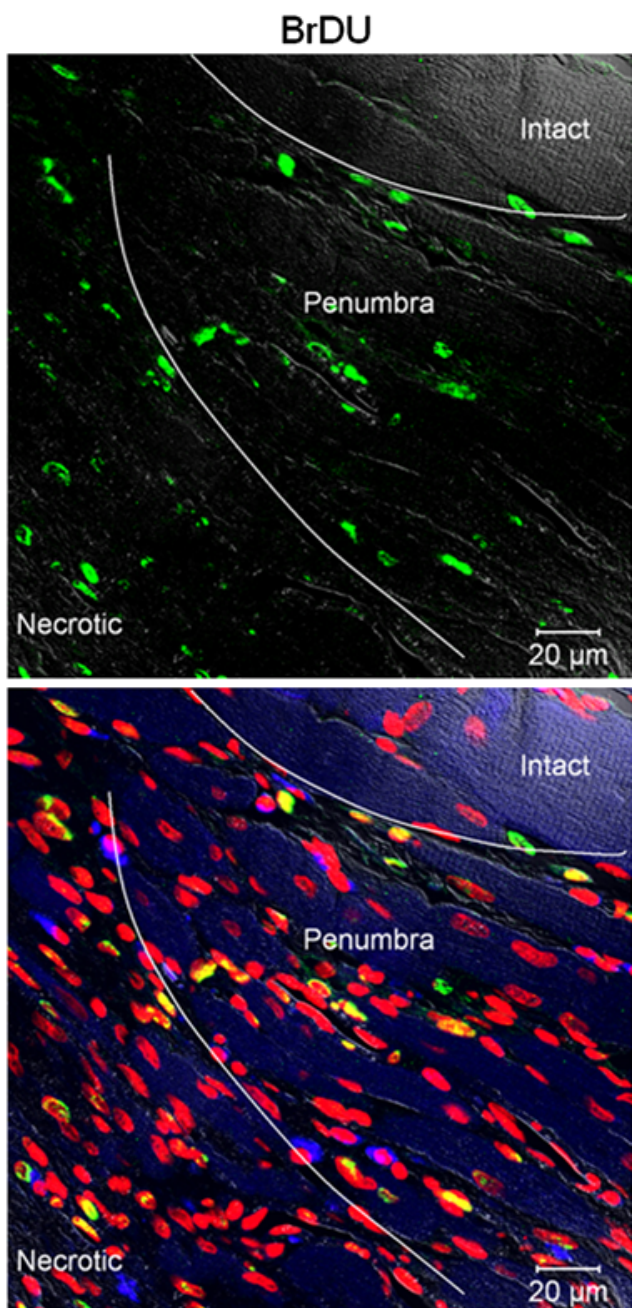

Merged

\section{Statistical analysis}

All values are reported as mean \pm sem with $n$ representing the number of experimental animals per group. Statistical analysis was performed using two-way ANOVA and Tukey post-hoc tests using Graphpad Prism (version 5) statistical software.

\section{Results}

One week after the trauma, different proliferating cell numbers can be seen in brain, muscle and gut (Fig. 3). The gut samples served as positive controls of BrDU staining and were intensive in all investigated segments. The percentage of proliferating cells in the basal layer of the gut mucosa was comparable between uninjured, single and repeated trauma groups, showing that the overall systemic cell-proliferation was not significantly disturbed by polytrauma. Immunohistochemical analysis of the brain 1 week after the trauma revealed very few BrDU stained nuclei (single trauma: $4.8 \pm 0.95 \%$, repeated trauma: $2.83 \pm$ $2.12 \%$ ) and no significant differences among the injured groups. The very low number of BrDU positive cells in the brain tissue did not allow reliable statistical analysis between single and repeated trauma experiments. In contrast, skeletal muscle tissue showed a much higher regenerative capacity than the brain. Control animals showed sporadic proliferating cells in skeletal muscle, which was significantly increased after trauma (Fig. 4). The percentage of BrDU positive cells after 1 week was $29.6 \pm 3.0 \%$ for the single trauma group and $28.0 \pm 2.5 \%$ for the second hit group (Fig. 4g). However, at this early timepoint the regenerating muscle tissue is undergoing debris phagocytosis and sterile inflammation, so it is assumed that some of the BrDU positive cells are macrophages, neutrophils or fibroblasts. Samples from the first and second hit groups exhibited intensive BrDU staining and the nuclei of the labeled cells often adopt flat morphology, which is a feature of myocyte nuclei and satellite cells (Fig. 4b, c). 


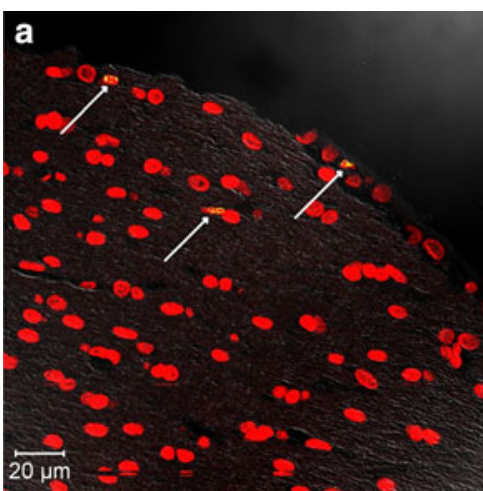

Brain

1 week after trauma

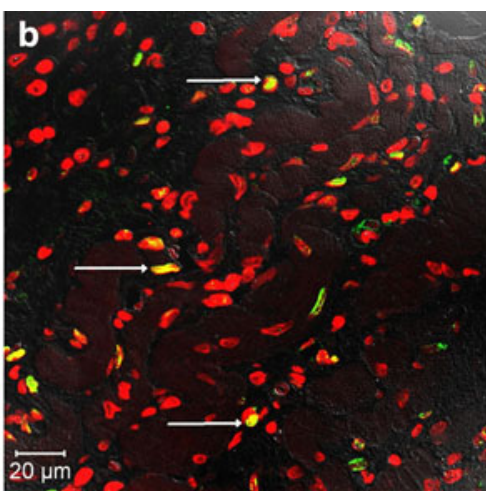

Muscle 1 week after trauma

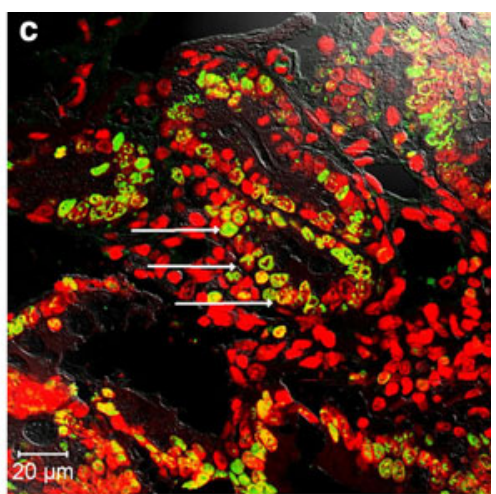

Gut

Unaffected control tissue
Fig. 3 Regional comparison of the proliferating cell numbers one week after the trauma. a Representative image, where a few BrDU positive cells can be seen on the surface of the brain and in the lesion

After the last trauma, when the acute phase was over, the majority of $\mathrm{BrDU}$ cells were observed in myofibers (Fig. 4e, f). After 5 weeks, the percentage of BrDU positive cells was $14.5 \pm 2.2 \%$ and $13.9 \pm 1.8 \%$ (Fig. $4 \mathrm{~g}$ ). The values between the groups at the same time points did not differ, but the fall in the numbers of proliferating cells after 5 weeks was significant in both groups with $p<0.05$ ( $n=7$ /group). Laminin staining showed that several cells which were aligned with the myofibers were located under the basal lamina, indicating that they were satellite cells or myocites (Fig. 5).

\section{Discussion}

In the present study we investigated whether the native proliferation potential of brain and muscle tissue is affected when a second trauma hits the regenerating tissue. In the cerebral cortex, a very low number of proliferating cells can be observed in both single and repeated trauma groups. In skeletal muscle tissue, however, high numbers of proliferating cells are located at the trauma site, especially in the penumbra, which is the region where myofibers are newly formed. In our experiments we found that the percentage of proliferating cells did not decrease significantly after suffering a second injury, compared to the group receiving only one cold lesion injury. This observation applies to both investigated time points. Furthermore, we found that even though the levels of proliferated cells decreased by $\sim 50 \% 5$ weeks after the last injury, these cells were all incorporated into muscle fibers and contributed to newly formed myofibers (Fig. 5).

A common experimental protocol to explore the dynamics of satellite cells in the healing process is the repeated trauma model. Using this model, it was found that the number of satellite cells remained the same after penumbra. b Higher number of BrDU positive cells in muscle tissue. Gut samples (c) served as positive control for a high-turnover tissue. Arrows BrDU positive nuclei

repeated injuries, indicating that this population has a sufficient reserve for regeneration [17, 18]. These models, however, significantly differ from the repeated poly-trauma model we used, because in those previous studies the intervals between the repeated traumatic injuries were longer, hence they investigated the already-regenerated muscle's ability to cope with the next tissue injury. In contrast, our repeated poly-trauma model was used to investigate the effects of a second injury while the tissue was still recovering from the first trauma. The abovementioned studies found that after the regeneration is over, the number of proliferating satellite cells drops to the pretrauma level [5, 17-19]. This is also true after repeated bouts of injuries. In our experiment, trauma was repeated on the 7th day. At this time point, according to our investigation, newly forming myofibers with BrDU positive nuclei can be seen in the penumbra. Damaged muscle structure, however, was still easily distinguishable from both the necrotic and intact tissue. In this phase, injury might have decreased the number of proliferating cells, including the satellite population. The results, however, showed no significant reduction in the number of proliferating cells, thus we hypothesize that the surviving myogen precursors might reach an even higher activated stage to reproduce the lost progenitors. This speculation is supported by earlier results demonstrating that a minor secondary insult can exert a preconditioning effect on muscular stem cell activity in a polytrauma model $[18,20]$.

During the healing process, myogenic progenitors are not the only cells colonizing the trauma site. According to a recent study using BrDU labeling, non-myogenic cells, such as fibroblasts, are also present around the injury [21]. Scar tissue and fibrosis are created by fibrocytes producing Type I and III collagen [22], compromising the complete recovery of skeletal muscle [23, 24]. In addition, trauma also causes early neutrophil invasion, which is followed by 
Fig. 4 Traumatic injury increases the number of proliferating cells.

Representative combined immunohistochemistry images of operated muscle areas of the penumbra region. Red color represents the nuclear Hoechst staining and green color refers to BrdU staining. Colocalization of the signals (yellow color) represents the newly divided cells. Control samples did not exhibit any BrdU staining indicating the lack of proliferation $(\mathbf{a}, \mathbf{d})$. In contrast, intensive yellow staining was observed at 1 week (b, c) and still after 5 weeks (e, f). $\mathbf{g}$ The percentage of proliferating cells in the groups at the two investigated time points. Asterisks indicate $p<0.05$
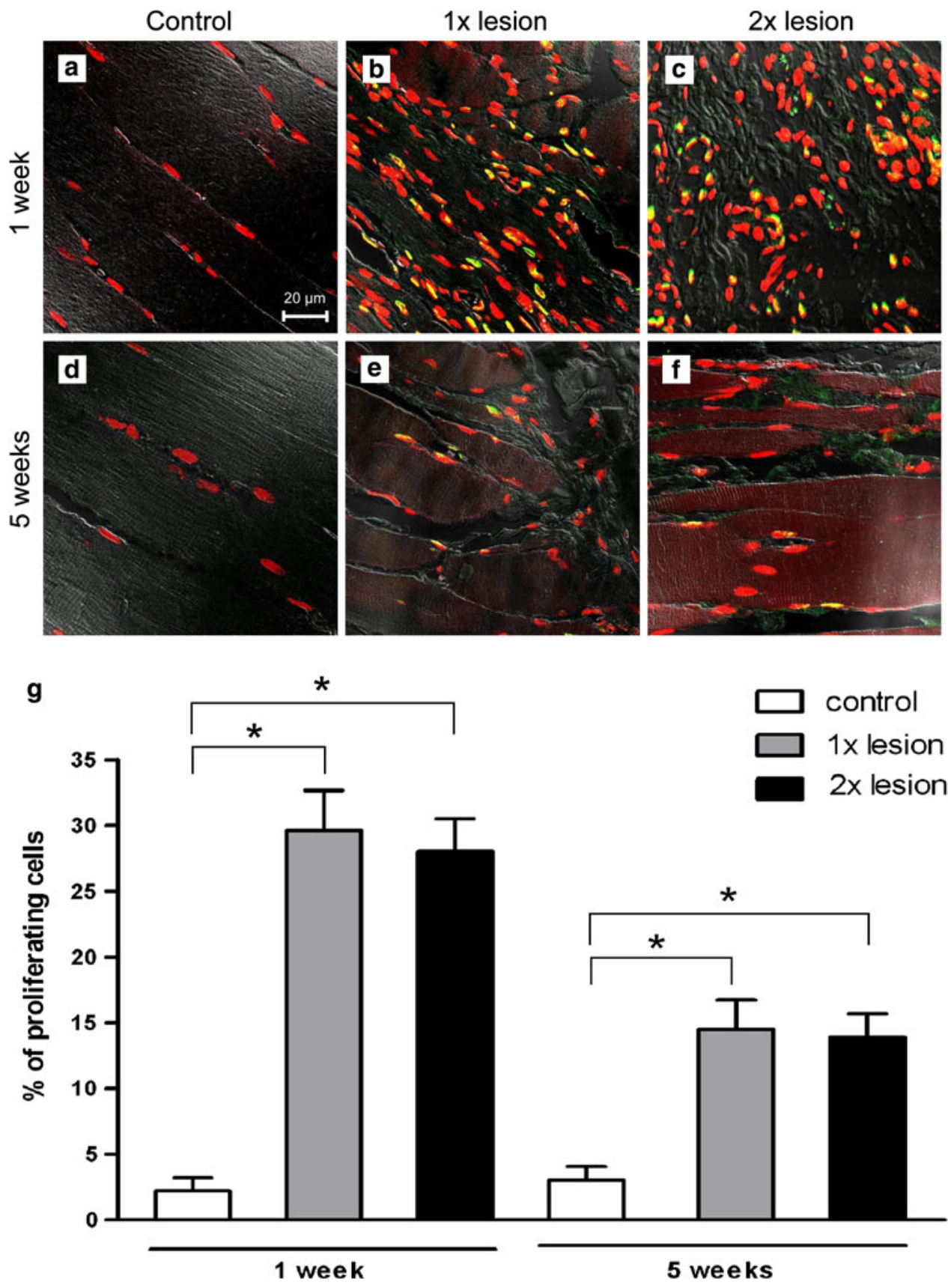

$\square$ control

$\square$ 1x lesion

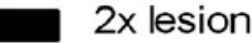

$2 x$ lesion

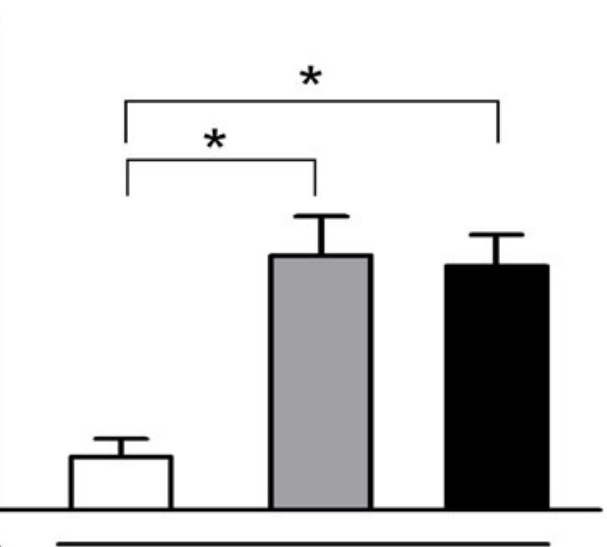

5 weeks macrophages $[21,25]$. Recent studies showed that neutrophils and macrophages were not only cleaning the tissue debris, but also have a significant role in satellite cell activation [26, 27]. Moreover, these inflammatory cells could persist in the tissue from days to weeks [20]. These cells were marked with the systemic BrDU administration and may contribute to the cell number counted as proliferating at 1 week. In addition, hematopoetic cell population also contributes to skeletal muscle regeneration [9-11]. These possibilities are to be taken into account when considering the approximately $50 \%$ decrease in BrDU positive cells at 5 weeks as well.
The 5th week after repeated trauma was chosen for the second time point based on previous studies. In those experiments, autotransplanted fibers finished regeneration 2 weeks after the trauma, but further healing was observed in repeatedly injured autotransplanted fibers, which ended 4 weeks after the last operation [20]. By this time the progenitor cells returned to the quiescent physiologic stage, and the new cells were formed. We expected that by the 5 th week the effects of the traumatic injuries would be eliminated, and regenerated muscle tissue can be investigated. We found a significant amount of previously proliferated cells incorporated into newly formed muscle fibers. 
Fig. 5 Newly formed muscle fiber with BrDU positive nuclei. Five weeks after the trauma, clear laminin staining and completely regenerated muscular structure can be investigated. Arrows show BrDU positive nuclei incorporated into the myofiber

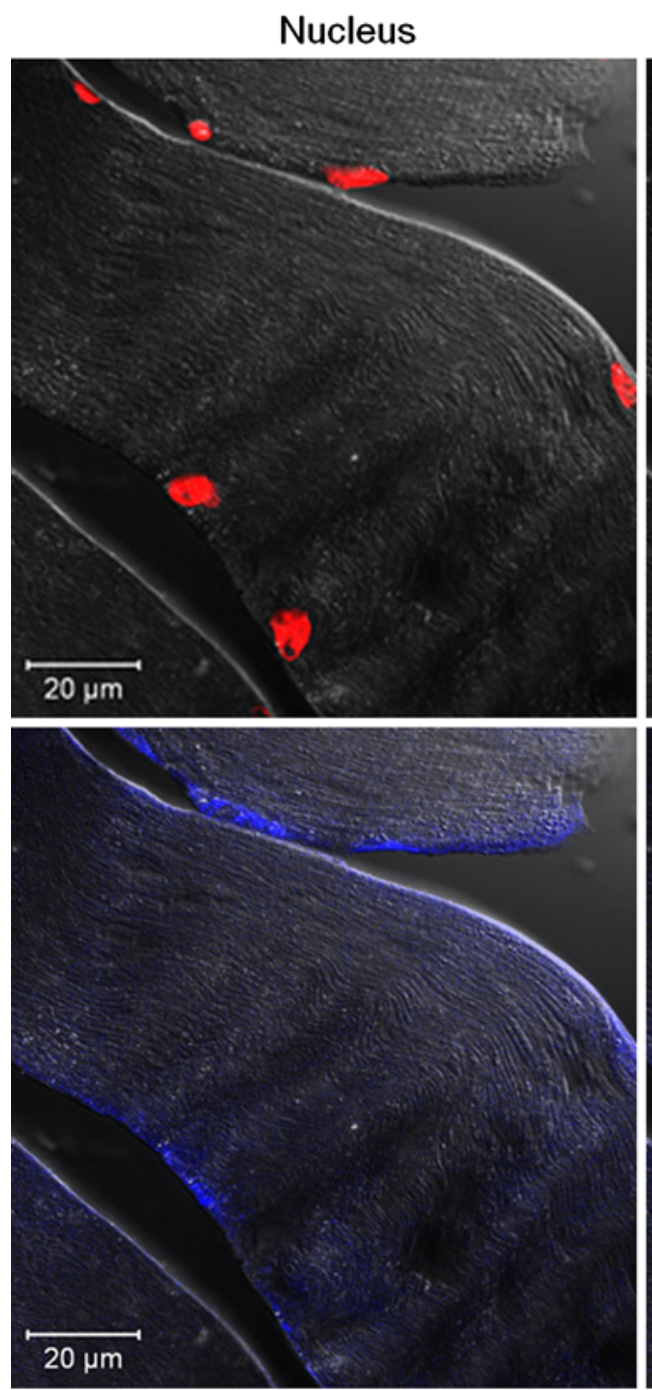

Laminin
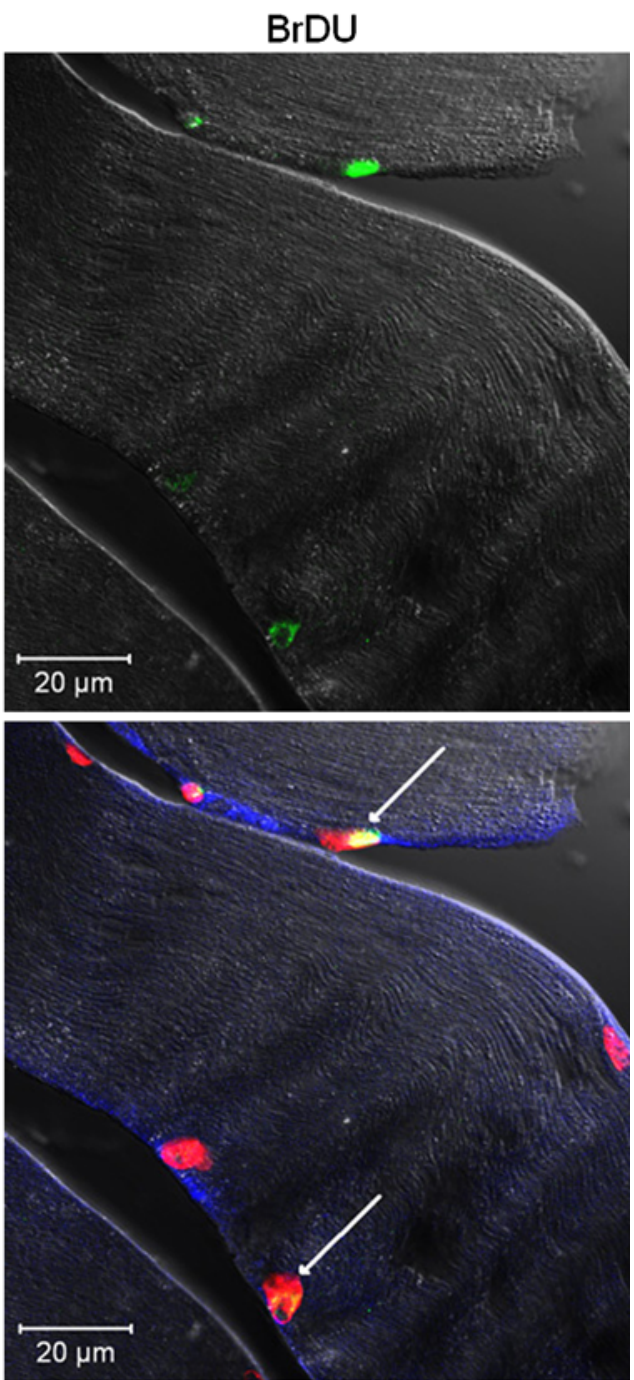

Merged
We conclude that repeated trauma does not affect the number of proliferating cells and around $50 \%$ of these cells are incorporated into newly formed myofibers in both single and repeated trauma groups, indicating that single and repeated polytraumatic injury does not impair the proliferation capabilities of myogenic precursors. These data suggest that the decreased healing potential after reconstructive surgery is not related to a decreased myogenic proliferation, but to other, possibly systemic causes.

Acknowledgments The present work was funded by grants from OTKA (Hungarian Scientific Research Fund) 45933, 049621, ÖAD 66öu5, TÁMOP 4.2.2-08/1/KMR-2008-0004, Hungarian-Singaporean cooperation grant (NKTH-A*STAR, acronym: CELLTHER), Öveges and Bolyai fellowships to Zs. L.

Conflict of interest statement The authors declare that they have no conflict of interest.
Open Access This article is distributed under the terms of the Creative Commons Attribution Noncommercial License which permits any noncommercial use, distribution, and reproduction in any medium, provided the original author(s) and source are credited.

\section{References}

1. Matthes G, Seifert J, Ostermann PA, Wurfel S, Ekkernkamp A, Wich M. Early death of the severely injured patient: a retrospective analysis. Zentralbl Chir. 2001;126(12):995-9.

2. Pape HC, Hildebrand F, Krettek C. Decision making and and priorities for surgical treatment during and after shock trauma room treatment. Unfallchirurg. 2004;107(10):927-36.

3. Gebhard F, Huber-Lang M. Polytrauma-pathophysiology and management principles. Langenbecks Arch Surg, 2008.

4. Gierer P, Hoffmann JN, Mahr F, Menger MD, Mittlmeier T, Gradl G, Vollmar B. Sublethal trauma model with systemic endotoxemia for the study of microcirculatory disorders after the second hit. J Surg Res. 2008;147(1):68-74. 
5. Charge SB, Rudnicki MA. Cellular and molecular regulation of muscle regeneration. Physiol Rev. 2004;84(1):209-38.

6. Collins CA, Olsen I, Zammit PS, Heslop L, Petrie A, Partridge TA, Morgan JE. Stem cell function, self-renewal, and behavioral heterogeneity of cells from the adult muscle satellite cell niche. Cell. 2005;122(2):289-301.

7. Mauro A. Satellite cell of skeletal muscle fibers. J Biophys Biochem Cytol. 1961;9:493-5.

8. Zammit P, Beauchamp J. The skeletal muscle satellite cell: stem cell or son of stem cell? Differentiation. 2001;68(4-5):193-204.

9. Doyonnas R, LaBarge MA, Sacco A, Charlton C, Blau HM. Hematopoietic contribution to skeletal muscle regeneration by myelomonocytic precursors. Proc Natl Acad Sci USA. 2004;101(37):13507-12.

10. Sherwood RI, Christensen JL, Weissman IL, Wagers AJ. Determinants of skeletal muscle contributions from circulating cells, bone marrow cells, and hematopoietic stem cells. Stem Cells. 2004;22(7):1292-304.

11. Camargo FD, Green R, Capetanaki Y, Jackson KA, Goodell MA. Single hematopoietic stem cells generate skeletal muscle through myeloid intermediates. Nat Med. 2003;9(12):1520-7.

12. Shah S, Ulm J, Sifri ZC, Mohr AM, Livingston DH. Mobilization of bone marrow cells to the site of injury is necessary for wound healing. J Trauma. 2009;67(2):315-21. (discussion 321-322).

13. Palermo AT, Labarge MA, Doyonnas R, Pomerantz J, Blau HM. Bone marrow contribution to skeletal muscle: a physiological response to stress. Dev Biol. 2005;279(2):336-44.

14. LaBarge MA, Blau HM. Biological progression from adult bone marrow to mononucleate muscle stem cell to multinucleate muscle fiber in response to injury. Cell. 2002;111(4):589-601.

15. Lacza Z, Horvath E, Busija DW. Neural stem cell transplantation in cold lesion: a novel approach for the investigation of brain trauma and repair. Brain Res Brain Res Protoc. 2003;11(3): $145-54$.
16. Rando TA. Stem cells, ageing and the quest for immortality. Nature. 2006;441(7097):1080-6.

17. Morlet K, Grounds MD, McGeachie JK. Muscle precursor replication after repeated regeneration of skeletal muscle in mice. Anat Embryol. 1989;180(5):471-8.

18. Schultz E, Jaryszak DL. Effects of skeletal muscle regeneration on the proliferation potential of satellite cells. Mech Ageing Dev. 1985;30(1):63-72.

19. Schultz E, McCormick KM. Skeletal muscle satellite cells. Rev Physiol Biochem Pharmacol. 1994;123:213-57.

20. Gulati AK. Pattern of skeletal muscle regeneration after reautotransplantation of regenerated muscle. J Embryol Exp Morphol. 1986;92:1-10.

21. Toumi H, F'Guyer S, Best TM. The role of neutrophils in injury and repair following muscle stretch. J Anat. 2006;208(4):459-70.

22. Best TM, Shehadeh SE, Leverson G, Michel JT, Corr DT, Aeschlimann D. Analysis of changes in mRNA levels of myoblastand fibroblast-derived gene products in healing skeletal muscle using quantitative reverse transcription-polymerase chain reaction. J Orthop Res. 2001;19(4):565-72.

23. Orchard J, Best TM. The management of muscle strain injuries: an early return versus the risk of recurrence. Clin J Sport Med. 2002;12(1):3-5.

24. Hurme T, Kalimo H, Lehto M, Jarvinen M. Healing of skeletal muscle injury: an ultrastructural and immunohistochemical study. Med Sci Sports Exerc. 1991;23(7):801-10.

25. Tidball JG. Inflammatory cell response to acute muscle injury. Med Sci Sports Exerc. 1995;27(7):1022-32.

26. St Pierre Schneider B, Brickson S, Corr DT, Best T. CD11b+ neutrophils predominate over RAM11+ macrophages in stretchinjured muscle. Muscle Nerve. 2002;25(6):837-44.

27. Merly F, Lescaudron L, Rouaud T, Crossin F, Gardahaut MF. Macrophages enhance muscle satellite cell proliferation and delay their differentiation. Muscle Nerve. 1999;22(6):724-32. 